J. Clin. Chem. Clin. Biochem.

Vol. 17, 1979, pp. 45-49

\title{
Bound and Free Light Chains in Serum from Patients Affected with Various Neurological Diseases
}

\author{
By Francine Bollengier
}

Laboratorium Fysiopathologie van het Zenuwstelsel, Vrije Universiteit Brussel, Brussels

(Received February 23/September 25, 1978)

Summary: Six immunological parameters, of which the most important are the quantitative distribution of the free light chains, and the kappa-lambda ratios of both bound and free light chains, were investigated in serum of patients affected with various neurological disorders and compared to controls.

Subacute sclerosing panencephalitis and viral encephalitis, which are diseases characterized by hyperimmunisation against definite antigens, are accompanied by a considerable quantitative increase of free light chains; in subacute sclerosing panencephalitis serum there is an increase of both free kappa and lambda chains, whereas in viral encephalitis serum the increase of free light chains was restricted to lambda chains.

There is a good correlation between the kappa-lambda ratio of, on the one hand, bound light chains and, on the other hand, free light chains for controls and subacute sclerosing panencephalitis; but in multiple sclerosis, amyotrophic lateral sclerosis and viral encephalitis, the ratios for bound light chains are totally different from ratios for free light chains. A general kappa increase, which we earlier reported for bound light chains in 16 cases of multiple sclerosis, was not confirmed by the investigation of an additional 26 cases: kappa decrease was also noticed in a considerable number of cases.

\section{Gebundene und freie leichte Ketten im Serum von Patienten mit verschiedenen neurologischen Erkrankungen}

Zusammenfassung: Sechs immunologische Größen - die wichtigsten sind die quantitative Verteilung der freien leichten Ketten und die Kappa-Lambda-Verhältnisse sowohl der freien als auch der gebundenen leichten Ketten wurden im Serum von Patienten mit verschiedenen neurologischen Störungen untersucht und mit denen von Kontrollpersonen verglichen.

Subakute sklerosierende Panencephalitis und virale Encephalitis - Erkrankungen, die durch Hyperimmunisierung gegen bestimmte Antigene charakterisiert sind - sind begleitet von einem beträchtlichen quantitativen Anstieg freier leichter Ketten: im Serum von an subakuter sklerosierender Panencephalitis Erkrankten findet sich ein Anstieg freier Kappa- und Lambda-Ketten, während der Anstieg der freien leichten Ketten im Serum an viraler Encephalitis Erkrankter auf die Lambda-Ketten beschränkt war.

Es besteht eine gute Korrelation zwischen dem Kappa-Lambda-Verhältnis sowohl der gebundenen leichten Ketten als auch der freien leichten Ketten bei den Kontrollpersonen und den an subakuter sklerosierender Panencephalitis Erkrankten; bei multipler Sklerose, amyotropher Lateralsklerose und viraler Encephalitis jedoch differieren die Verhältnissse für gebundene leichte Ketten völlịg von denen für freie leichte Ketten. Ein genereller Anstieg der Kappa-Ketten, den wir früher für gebundene leichte Ketten in 16 Fällen von multipler Sklerose beschrieben haben, konnte bei Untersuchung zusätzlicher 26 Fälle ñicht bestätigt werden: auch ein Abfall der Kappa-Ketten wurde in einer beträchtlịchen Zạhl der Fälle festgestellt.

\section{Introduction}

In previous papers $(1,2,3)$ we investigated oligoclonal immunoglobulins, light chain ratios, free light chains, the presence of the double ring formation in single radial immunodiffusion, agar gel electrophoresis and thin layer isofocusing pattern in cerebrospinal fluid and serum from patients affected with various neurological diseases.

For the cerebrospinal fluid there seemed to be a correlation between the frequency of the presence of free light chains and the degree of severity of the immunological processes, or of hyperimmunisation, since this 
frequency was highest in subacute sclerosing panencephalitis, neurosyphilis and viral encephalitis. We were not then able to evaluate the free light chains in serum from patients with the same neurological disorders, for the lack of sufficient assays in amyotrophic lateral sclerosis cases and controls.

In the present paper we should now like to report the quantitative distribution of free light chains, and the kappa-lambda ratio of bound and of free light chains in the serum of patients grouped according to 4 different neurological diseases, together with earlier results of IgG content and agar gel electrophoresis pattern (3).

Elsewhere (3) we examined 16 sera of multiple sclerosis patients and found a kappa increase for the kappa-lambda ratios of bound light chains. We stated that this particular feature, if thoroughly investigated on a larger number of sera, could become important for the diagnosis of multiple sclerosis. Consequently, in this paper we considered 42 cases of multiple sclerosis in order to evaluate the validity of the statement.

\section{Material and Methods}

We considered the following neurological diseases:

1. amyotrophic lateral sclerosis

2. multiple sclerosis

3. subacute sclerosing panencephalitis

4. viral encephalitis.

Diagnosis was based on the clinical course of the diseases, on the electro-encephalogram, thorough routine examination of the serum and cerebrospinal fluid (total proteins, cell counting, etc.), agar gel electrophoresis, and when necessary, on titration of the viral antibodies.

Pathological sera were used immediately or kept frozen at $-35^{\circ} \mathrm{C}$. Control serum was taken from healthy donors and assayed immediately. Agar gel electrophoresis was carried out according to Wieme (4). The IgG content was measured by single radial immunodiffusion, using Tripartigen plates ${ }^{1}$ ).

The bound and free light chain determinations were performed by single radial immunodiffusion in agar plates with incorporated bound and free light chain antiserum as described previously (1). The standard curve was established with several dilutions of reference kappa and lambda Bence-Jones proteins (1).

The statistical method used to investigate the different populations was the following: since a normal distribution cannot be assumed in pathological states, we employed non parametrics statistics, i. e. the U-test of Wilcoxon ${ }^{2}$ ).

\section{Results}

In order to avoid a multitude of tables, all the results were grouped in a unique table in the form of mean values; the significant differences between controls and pathological values were calculated by the non parametric Wilcoxon test (tab. 1). Nevertheless a global description of individual values will be given.

1) Tripartigen - IgG TDS/03 - Behringwerke A. G. - Marburg/ Lahn.

2) Documenta Geigy - Tables scientifiques - Basel.
For the control cases, IgG content and $k b / \lambda b^{3}$ ) were as reported elsewhere $(1,3)$. Free kappa chains and lambda chains were present in all cases. The kappalambda ratios of free light chains were very close to those of bound chains.

The same parameters are reported for 11 cases of amyotrophic lateral sclerosis. Three cases had slightly elevated IgG, one showed decreased IgG, but all $\kappa \mathrm{b} / \lambda \mathrm{b}$ were lower than those of the controls.

Free $k$-chains were increased when compared to contiol values, but free $\lambda$-chains had almost the same distribution as controls, notwithstanding a few exceptions. No oligoclonal immunoglobulins were recorded.

We examined 42 cases of multiple sclerosis and this represents a much larger group than we reported in an earlier paper (3). They were grouped according to their $\left.\kappa b / \lambda b^{4}\right)$.

In group I of the 13 cases, 9 had normal IgG levels, 3 showed decreased levels and one had slightly elevated $\mathrm{IgG}$. All the $\kappa \mathrm{b} / \lambda \mathrm{b}$ were, as mentioned above, higher than or equal to control values.

Free $k$-chains were decreased compared to the controls, whereas free $\lambda$-chains showed almost no change. 5 of 11 $\kappa \mathrm{f} / \lambda \mathrm{f}$ were frankly $\lambda$-predominant, while patient 8 presented a pure $\kappa$-chain population.

In agar gel electrophoresis one serum showed definite oligoclonal immunoglobulins and three other samples showed a tendency towards fractionation.

In group II, 3 out of 29 cases showed decreased IgG and 9 showed increased levels. $k \mathrm{~b} / \lambda \mathrm{b}$ were widely spread and 13 of them frankly $\lambda$-predominant. Free $k$-chains were increased in almost every case when compared to controls, but the free $\lambda$-chains were within the range of control values. In agar gel electrophoresis three sera showed oligoclonal immunoglobulins and one showed a tendency towards fractionation.

The mean values of the multiple sclerosis parameters grouped in table 1 clearly illustrate these findings.

As far as the 18 subacute sclerosing panencephalitis patients are concerned, the well known IgG increase is once more confirmed $(1,3) . \kappa \mathrm{b} / \lambda \mathrm{b}$ were considerably spread, ranging from 1.2 to 5.4. Free $k$ - as well as $\lambda$-chains were increased when compared to control values. Five sera were $\lambda$-predominant, three displayed only free $\lambda$-chains, one only free $k$-chains and two showed a considerable $k$-increase.

In agar gel electrophoresis 17 out of 18 cases showed fractionation. As demonstrated elsewhere (3) the IgG values of 11 sera from patients affected with viral encephalitis were considerably spread and $k b / \lambda b$

3) $\kappa b / \lambda b=k a p p a-l a m b d a$ ratio of bound light chains.

4) Groúp I: $k \mathrm{~b} / \lambda \mathrm{b}$ multiple sclerosis $>\kappa \mathrm{b} / \lambda \mathrm{b}$ controls Group II: $\kappa \mathrm{b} / \lambda \mathrm{b}$ multiple sclerosis $<\kappa \mathrm{b} / \lambda \mathrm{b}$ controls. 
Tab. 1. Mean values and significant differences between control and pathological sera for $2 \alpha=0.01,2 \alpha=0.02$.

\begin{tabular}{|c|c|c|c|c|c|c|c|}
\hline & & IgG & $\kappa \mathrm{b} / \lambda \mathrm{b}$ & Free $k$-chains & Free $\lambda$-chains & $\kappa \mathrm{f} / \lambda \mathrm{f}$ & $\begin{array}{l}\text { Agar gel } \\
\text { electro- } \\
\text { phoresis }\end{array}$ \\
\hline & & {$[\mathrm{g} / 1]$} & $\overline{\mathbf{x}} /$ median & {$\left[\begin{array}{l}{[\mathrm{mg} / \mathrm{l}]} \\
\overline{\mathrm{x}} / \mathrm{median}\end{array}\right.$} & {$\left[\begin{array}{l}{[\mathrm{mg} / \mathrm{l}]} \\
\mathrm{x} / \mathrm{median}\end{array}\right.$} & $\overline{\mathbf{x}} /$ median & $\begin{array}{l}\% \text { fractiona- } \\
\text { tion }\end{array}$ \\
\hline Controls & $\mathrm{n}=20$ & $11.96 / 12.15$ & $2.28 / 2.25$ & $98.80 / 87.00$ & $42.40 / 40.00$ & $2.59 / 2.45$ & 0 \\
\hline $\begin{array}{l}\text { Amyotrophic } \\
\text { lateral sclerosis }\end{array}$ & $n=11$ & $12.49 / 12.70$ & $1.46 / 1.5 .0^{+}$ & $112.73 / 95.00$ & $46.82 / 28.00$ & $3.53 / 3.60$ & 0 \\
\hline $\begin{array}{l}\text { Multiple sclerosis } \\
\text { (group I)* }\end{array}$ & $\mathrm{n}=13$ & $11.54 / 12.20$ & $3.10 / 3.00^{+}$ & $79.08 / 67.00$ & $53.62 / 60.00$ & $1.57 / 1.50^{+}$ & 7.6 \\
\hline $\begin{array}{l}\text { Multiple sclerosis } \\
\text { (group II)** }\end{array}$ & $\mathrm{n}=29$ & $13.39 / 12.20$ & $1.21 / 1.10^{+}$ & $138.14 / 125.00^{-}$ & $45.79 / 40.00$ & $3.87 / 3.50^{-}$ & 13.8 \\
\hline $\begin{array}{l}\text { Subacute sclerosing } \\
\text { panencephalitis }\end{array}$ & $\mathrm{n}=18$ & $17.78 / 17.30^{+}$ & $2.38 / 2.20$ & $152.85 / 106.00$ & $142.84 / 71.00^{+}$ & $2.03 / 1.60$ & 96.0 \\
\hline Viral encephalitis & $\mathrm{n}=11$ & $10.90 / 9.50$ & $1.72 / 1.70^{+}$ & $102.00 / 80.00$ & $288.30 / 155.00^{+}$ & $0.82 / 0.16^{+}$ & 17.0 \\
\hline
\end{tabular}

+ pathological values differ from controls for $2 \alpha=0.01$ (Wilcoxon test)

- pathological values differ from controls for $2 \alpha=0.02$

* group I: $\kappa b / \lambda b>\kappa b / \lambda b$ controls

** group II: $\kappa \mathrm{b} / \lambda \mathrm{b}<\kappa \mathrm{b} / \lambda \mathrm{b}$ controls

values were slightly decreased in comparison to mean control ones.

Free $\lambda$-chains were greatly increased when compared to control values, whereas free $k$-chains were only slightly increased. Consequently $\kappa \mathrm{f} / \lambda \mathrm{f}$ were particularly $\lambda$-predominant.

Table 1 gives the mean values, the significant differences between control and pathological sera and the frequency of appearance of fractionated immunoglobulins in agar gel electrophoresis. For the IgG values, all the earlier results we reported in se rum (3) are confirmed: only subacute sclerosing panencephalitis differs significantly from controls,

With respect to the $\kappa b / \lambda b$, earlier findings (3) are also confirmed, although we divided the much larger group of multiple sclerosis into groups I and II; for both groups the $\kappa b / \lambda b$ differed significantly from controls.

When considering the free $k$-chains, only multiple sclerosis-group II differed from controls; with respect to the free $\lambda$-chains, significant differences from controls were found in subacute sclerosing panencephalitis and viral encephalitis.

Multiple sclerosis and viral encephalitis display $k \hat{f} / \lambda f$, which are significantly different from those of controls.

Finally, the appearance of fractionated immunoglobulins showed a high incidence in subacute sclerosing panencephalitis sera, increasing from 14 to 18 cases. Screening of a large multiple sclerosis group revealed the presence of fractionated IgG in group I as well as in group II.

\section{Discussion}

In the group of neuralogical diseases we investigated; only subacute sclerosing panencephalitis sera displayed
IgG values which were significantly different from controls.

However, when grouping multiple sclerosis sera as described above, individual increased IgG values occured more often in group II than in group I; consequently mean IgG values in group II were slightly higher than in group $I$.

On the one hand, all the observations we made elsewhere (3) for $\kappa b / \lambda b$ in sera from patients affected with amyotrophic lateral sclerosis, subacute sclerosing panencephalitis and viral encephalitis were confirmed: i. e., serum $k \mathrm{~b} / \lambda \mathrm{b}$ in the range of controls were only found in subacute sclerosing panencephalitis.

The serum $k b / \lambda b$ were decreased in viral encephalitis and amyotrophic lateral sclerosis.

On the other hand, we were unable to reinforce our earlier statement of a general kappa-increase in serum from multiple sclerosis patients: when investigating an additional 26 cases, we observed decreased as well as increased $\kappa \mathrm{b} / \lambda \mathrm{b}$.

For the first time in the course of our investigations we noticed 4 multiple sclerosis sera with definite oligoclonal immunoglobulins and 4 others with a tendency towards fractionation.

However the main subject of this paper is the presence and the quantitative distribution of free light chains in serum. Presence of free light chains in serum of healthy donors has been reported by several authors $(5,6,7)$. However the quantitative values of free light chains that we observed in control serum are not in agreement with earlier findings: ours are much higher. The fact that we used antisera directed exclusively against free light chains, and finally that we used Bence-Jones reference proteins could perhaps explain 
this fact. Discrepancies in results according to different techniques used have been frequently noticed.

An analogous observation holds true for the ratio of free kappa-lambda light chains; the ratios we observed are much higher than those of earlier investigators $(7,8)$.

Nevertheless, the $\kappa f / \lambda f$ we obtained for controls are in good agreement with the $\kappa \mathrm{b} / \lambda \mathrm{b}$. If it is true, as has been advanced by Shapiro et al. (9) that free light chains are synthesized de novo rather than being a breakdown product of intact immunoglobulins, one must accept that in control sera more kappa light chains are synthesized than lambda light chains, in order to cope with the higher demand for kappa chains since serum immunoglobulins are $\kappa$-predominant. The good correlation between $\kappa \mathrm{f} / \lambda \mathrm{f}$ and $\kappa \mathrm{b} / \lambda \mathrm{b}$ seems to confirm this hypothesis.

In the neurological diseases that we investigated, the underlying mechanism responsible for the distribution of free light chains seems far from clear.

In amyotrophic lateral sclerosis five sera had increased free $\kappa$-chains, four had increased free $\lambda$-chains and one had particularly decreased $\lambda$-chains. The distribution of $\kappa \mathrm{f} / \lambda \mathrm{f}$ was in sharp contrast to the $\kappa \mathrm{b} / \lambda \mathrm{b}$.

In multiple sclerosis group I only the free $\lambda$-chain distribution was in good agreement with the controls; as in amyotrophic lateral sclerosis, $k \mathrm{~b} / \lambda \mathrm{b}$ were entirely different from $\kappa f / \lambda f ; \kappa b / \lambda b$ showed a kappa increase and $\kappa f / \lambda f$ a kappa decrease when compared to control values.

In group II the situation was the inverse, except for the free lambda light chain range, which was once more comparable to the control one.

Subacute sclerosing panencephalitis sera are characterized by a considerable increase of both free kappa and lambda chains in a great many individual cases, although mean kappa light chain values are not significantly different from controls for the considered $\alpha$-limits. Subacute sclerosing panencephalitis is the only neurological disease where the mean $\kappa \mathrm{b} / \lambda \mathrm{b}$ and the mean $\kappa f / \lambda f$ are in good correlation with each other.

Finally, when considering viral encephalitis sera it is obvious that the free $\lambda$-chains are greatly increased. This disease is also characterized by $k \mathrm{f} / \lambda \mathrm{f}$ which are very low in most cases. At a cellular level the production of excess light chains could be due to either the synthesis of only light chains by some cells while others make equimolar amounts of both polypeptide chains, or to the synthesis of more light than heavy chains by all cells; the latter possibility seems more likely, since Bernier \& Cebra (10) presented immunofluorescent evidence that in humans all $\gamma$-globulin producing cells contain both types of polypeptide chains. Light chains are released autonomously from polyribosomes into a pool of free light chains. Askonas et al. (11) demonstrated that during immunoglobulin synthesis light chain formation modulates heavy chain formation. One may perhaps conclude that in normal conditions the small pool of light chains serves as an intermediate of IgG molecules. Shapiro et al. (9) reported that cell suspensions of hyperimmunized rabbit lymph nodes synthesized and secreted in the culture medium an excess of free light chains. This explanation may thus account for the appearance of free light chains in diseases in which an immune mechanism is playing a role. However it is difficult to know whether the light chains are produced by cells making specific antibodies to the disease. Large amounts of free light chains were found in sera and urine of patients affected with systemic lupus erythematosus and in the synovial fluids and urine of patients with rheumatoid arthritis $(12,13)$. In the patients with rheumatoid arthritis, the light chains were most probably synthesized at sites of inflammation. In systemic lupus erythematosus increased type lambda protein was observed and one could advance the hypothesis that this type of light chain could be characteristic of the antibodies elaborated in this disorder.

We have already observed that diseases such as subacute sclerosing panencephalitis and viral encephalitis, where hyperimmunisation has been established against measles and herpes virus respectively, were characteriżed by a considerable increase of free lambda light chains. Moreover, in a previous paper (1) we stated that particular immunoglobulins, predominantly $\lambda$-immunoglobulins, are possibly synthesized in the cerebrospinal fluid of subacute sclerosing panencephalitis; this fits well with the present results from the serum of subacute sclerosing panencephalitis patients.

In multiple sclerosis, a demyelinating disease, the great number of clues to the pathogenesis of the disease is frequently conflicting. One of them is that multiple sclerosis could be a slow virus disease, or rather a virus induced immune disease. However the presumed viral immunisation is probably not to be compared to the phenomenon of hyperimmunisation, as is noticed in subacute sclerosing panencephalitis and viral encephalitis. It seems likely that as far as the free light chain pool in multiple sclerosis sera is concerned, we are very near the free light chain distribution of controls.

This could mean that in multiple sclerosis specific viral antibodies or antibodies against tissue antigens are almost exclusively restricted to the central nervous system.

\section{Conclusion}

1. All the observations we reported earlier $(1,3)$ for IgG content and $\kappa b / \lambda b$ in serum from controls and from patients with various neurological diseases were confirmed, except for multiple sclerosis; indeed, when 


\section{Walter de Gruyter Berlin-New York}

\section{S. B. Pal} (Editor)

\section{Enzyme Labelled Immunoassay of Hormones and Drugs}

Proceedings of the International Symposium on Enzyme Labelled Immunoassay of Hormones and Drugs, Ulm, West Germany, July 10 and $11,1978$.

1978. $17 \mathrm{~cm} \times 24 \mathrm{~cm} . X X V I, 475$ pages. Numerous illustrations. Hard cover DM 130,-; \$68.50 ISBN 3110075393

Over the past three decades, there has been tremendous progress in the discovery and development of analytical methods for the quantitative determination of minute amounts of various substances in biological samples.

The introduction of competitive protein binding technique and radioimmunoassay have made it possible to measure many hormones and drugs at extremely low concentrations, thus opening a new avenue of sensitive assays.

As these techniques involve the use of radioactive isotopes, analytical laboratories allied to medicine are faced with a serious . health hazard.

Enzyme immunoassay has essentially solved this problem because no radiation hazard or disposal difficulties are involved as this procedure is free from the use of radioactive isotopes.

Enzyme immunoassay methods are specific and sensitive, some of these procedures being as sensitive as radioimmunoassay. The laboratory equipment required is relatively inexpensive, readily available, and the reagents are reasonably priced and have a long shelf life. Technical manipulations are simple and the assays may be very rapid, as separation steps are not generally required.

The variety of labels available may allow multiple simultaneous asssays to be performed and it appears that there is a potential for automating the enzyme immunoassay methods.

The aim of holding this International Symposium on Enzyme Labelled Immunoassay of Hormones and Drugs, was to invite a number of speakers from various countries who are working in this rapidly developing field, and to have an opportunity to listen to their experiences with this technique; also, to discuss the possibility of further developmẹntș. 

investigating a larger group of multiple sclerosis sera we no longer observed a general kappa increase.

2. The agar gel electrophoresis pattern of immunoglobulins from sera of patients affected with amyotrophic lateral sclerosis, subacute sclerosing panencephalitis and viral encephalitis was once more confirmed, but for multiple sclerosis patients we now observed a few sera with definite oligoclonal immunoglobulins and several with a tendency towards fractionation.

In a previous paper (3) we suggested that in multiple sclerosis oligoclonal immunoglobulins could be present in the serum, but that the few clones, possibly present, were not yet sufficiently predominant in the heterogeneous background IgG.

According to the present findings in multiple sclerosis sera, this seems to be true for a few cases at least.

3. We studied the quantitative distribution of free light chains in 20 control sera, and assumed, on the one hand, that in normal conditions the small pool of free light chains perhaps serves as an intermediate of IgG molecules; on the other hand, we stated that in order to cope with the higher demands for kappa chain, more kappa chains are synthesized than lambda chains.

4. In neurological diseases, which are accompanied with hyperimmunisation, such as subacute sclerosing panencephalitis and viral encephalitis, we advanced the hypothesis that a particular type of free light chain, which becomes especially predominant in the pool of free light chains, could be characteristic of the specific antibodies elaborated in the disorder, in serum as well as in cerebrospinal fluid.
Elsewhere (3) we considered the presence of free light chains in the cerebrospinal fluid as an index of either hyperimmunisation, or strong immunological processes in the central nervous system. On the basis of the results we now report for subacute sclerosing panencephalitis and viral encephalitis we may perhaps conclude that prolonged residence of the virus in the organism also affects the distribution of free light chain in the serum.

This is not so surprising since in those diseases serum, as well as cerebrospinal fluid, are characterized by elevated titers in viral antibodies.

5. In multiple sclerosis the situation is controversial: on the one hand serum free light chains are not increased to such an extent as in subacute sclerosing panencephalitis and viral encephalitis, and on the other hand serum from multiple sclerosis patients is not characterized by especially high titers of antibodies against a variety of known viral antigens (15).

Although specific antibodies, possibly of the kappa chain type, are most probably synthesized in the central nervous system of multiple sclerosis patients $(1,2,3$, 16), it seems less likely that humoral antibodies of central nervous system specificity directly related to the disease are elaborated.

In multiple sclerosis, the viral etiology, although strongly suspected, has never been clearly demonstrated and demyelination is the paramount factor; this affects solely white matter, whereas in subacute sclerosing panencephalitis and viral encephalitis both white and gray matter are involved by inflammation, the responsible antigen being most commonly a virus.

\section{References}

1. Bollengier, F., Lowenthal, A. \& Henrotin, W. (1975), Z. Klin. Chem. Klin. Biochem. 13, 305-310.

2. Bollengier, F., Delmotte, P. \& Lowenthal, A. (1976), J. Neurol. 212, 151-158.

3. Bollengier, F., Rabinovitch, N. \& Lowenthal, A. (1978), J. Clin. Chem. Clin. Biochem. 16, 165-173.

4. Wieme, R. J. (1965), Agar gel electrophoresis, Elsevier Publishing Company, Amsterdam.

5. Berggărd, I. \& Edelman, G. M. (1963), Biochemistry 49 , $330=337$.

6. Berggạard, I. \& Peterson, P. A. (1968), J. Biol. Chem. 244, 4299-4307.

7. Sọlling, K. (1975), Scand. J. Clin. Lab. Invest. 35, 407-412.

8. Epstein, W. V., Fong, S. W. \& Tan, M. (1966), Immunology $10,259-270$.

9. Shapiro, A. L., Scharff, H. D., Maizel, J. V. \& Uhr, J. W. (1966), Nature 211, 243-245.

10. Bernier, G. M. \& Cebra, J. J. (1965), J. Immunology 95, $246-253$.

11. Askonas, B. A. \& Williamson, A. R. (1967), Nature 216, 264-267.

12. Epstein, W. V. \& Tan, M. (1966), Arthritis and Rheumatism 9, 713-719.

13. Cooper, A. \& Bluestone, R. (1968), Ann. Rheum. Dis. 27, 537-543.

14. Oldstone, M. B. A., Wilson, C. B., Perrin, L. H. \& Norris, F. H. (1976), Lancet $I I, 168-172$.

15. Caspary, E. A. (1977), Br. Med. Bull. 33, 50-53.

16. Thompson, E. J. (1977), Br. Med. Bull. 33, 28-33.

Dr. F. Bollengier Laboratorium Fysiopathologie van het Zenuwstelsel Vrije Universiteit Brussel

Eversstraat, 2

B-1000 Brussel 
.

. . 